\title{
Transient Hypertension and Sustained Tachycardia in Mice Housed Individually in Metabolism Cages
}

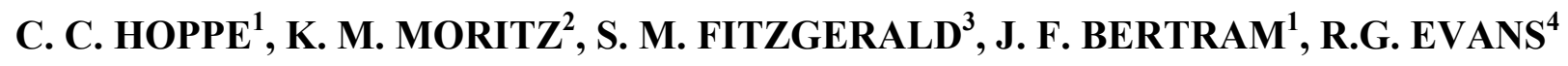 \\ ${ }^{1}$ Department of Anatomy and Developmental Biology, Monash University, Melbourne, Victoria, \\ ${ }^{2}$ School of Biomedical Health Sciences, University of Queensland, Brisbane, Queensland, ${ }^{3}$ Stroke \\ Epidemiology, Baker IDI Heart and Diabetes Institute, Melbourne, Victoria, and ${ }^{4}$ Department of \\ Physiology, Monash University, Melbourne, Victoria, Australia
}

Received August 27, 2007

Accepted November 21, 2007

On-line January 17, 2008

\section{Summary}

The novel environment of a metabolic cage can be stressful for rodents, but few studies have attempted to quantify this stressresponse. Therefore, we determined the effects on mean arterial pressure (MAP) and heart rate (HR), of placing mice of both sexes in metabolism cages for 2 days. After surgical implantation of a carotid artery catheter mice recovered individually in standard cages for 5 days. Mice then spent 2 days in metabolism cages. MAP and HR were monitored in the standard cage on Day 5 and in metabolism cages on Days 6-7. MAP increased by $18 \pm 3$ and $22 \pm 4 \%$, while HR increased by $27 \pm 4$ and $27 \pm 6 \%$, in males and females, respectively, during the first hours after cage switch. MAP decreased to baseline in the fourth and eighth $h$ following metabolism cage switch in males and females, respectively. However, HR remained significantly elevated in both sexes during the entire two-day period in metabolism cages. Females had lower MAP than males both pre- and postmetabolism cage switch, but there were no sex differences in HR. These results demonstrate sustained changes in cardiovascular function when mice are housed in metabolism cages, which could potentially affect renal function.

\section{Key words}

Mouse $\bullet$ Metabolic cage $\bullet$ Stress $\bullet$ Hypertension $\bullet$ Sex

\section{Corresponding author}

R. Evans, Department of Physiology, School of Biomedical Sciences, Monash University, Victoria, 3800, Australia. Fax: 61-399052547. E-mail: Roger.Evans@med.monash.edu.au

\section{Introduction}

The use of metabolism cages to determine renal function is valuable for phenotypic characterization in rats (Vadiei et al. 1990, Daull et al. 2005a,b, Sakly et al. 2005). With the current widespread use of genetically modified mice, reports of metabolism cage studies of mouse renal physiology are on the increase (Fenton et al. 2005, Fenton and Knepper, 2007). Implicit in the use of this methodology is the presumption that neurohumoral and cardiovascular function are relatively normal in mice housed in metabolism cages. However, evidence exists to suggest altered neurohumoral control in rats housed in metabolism cages (Gil et al. 1999, Armando et al. 2001, Eriksson et al. 2004, Armando et al. 2007). Whilst no report exists, to our knowledge, of cardiovascular responses to placing mice into metabolism cages, results from studies investigating cage-switching in mice have shown transient increases in arterial pressure and heart rate (HR) as well as complex neurophysiological responses (Lee et al. 2004a,b). However, this paradigm may not necessarily reflect the housing conditions of metabolism cages. Importantly, changes in cardiovascular and neurohumoral function may lead to altered renal function and so confound the very measurement metabolism cages provide. There is also strong evidence that there are differences in cardiovascular control between male and female mice (Xue et al. 2005). However, it is not known whether the cardiovascular effects of housing mice in metabolism cages differ between the sexes. Indeed, metabolism cage studies in 
both rats and mice have focused largely on male animals (Vadiei et al. 1990, Bosque et al. 1994, Brunner et al. 1994, Gil et al. 1999, Armando et al. 2001, Bamberg et al. 2001, Eriksson et al. 2004, Bae et al. 2005, Armando et al. 2007) with only a few studies investigating female animals (Leung et al. 2004, Chen et al. 2005) and/or both sexes (Gomez-Sanchez and Gomez-Sanchez 1991). The aim of our current study, therefore, was to characterize the effects of housing in metabolism cages, on mean arterial pressure (MAP) and HR in male and female mice. The experiment was designed to mimic the paradigm of most studies investigating renal function. Following 5 days of recovery after insertion of a carotid artery catheter for long-term measurement of arterial pressure and HR, mice were placed into metabolism cages for two days. To ensure that our observations reflected the effects of the environment of the metabolism cage rather than isolation, mice were housed individually in standard cages prior to being placed in metabolism cages.

\section{Methods}

Animals

Experiments were conducted in accordance with the National Health and Medical Research Council of Australia 'Australian Code of Practice for the Care and Use of Animals for Scientific Purposes' (7 $7^{\text {th }}$ edition, 2004) and were approved by the Monash University, Biochemistry, Anatomy and Microbiology Animal Ethics Committee. Twenty C57BL/6J /129sv offspring (13 males, 7 females) were studied at about 37 weeks of age. These offspring were part of a larger study examining the effects of different diets on cardiovascular physiology. Because the changes in MAP and HR observed during housing in metabolism cages were similar in all dietary groups, the data were pooled so we could examine whether these responses were sex-dependent. Prior to experiments, mice of either sex were housed in groups of 3-4 in standard boxes enriched with saw-dust bedding. Food pellets and water were given ad libitum. Mice chosen for experimentation were randomly selected from each box of 3-4 group-housed mice. Only 1-2 mice were chosen from each of these boxes. Mice were derived from 9 different litters.

\section{Habituation}

One to two weeks prior to surgery for cannulation of a carotid artery for arterial pressure measurement (see below), mice were habituated in individual metabolism cages for $24 \mathrm{~h}$. The metabolism cages were made of stainless steel and wire and were obtained from Lenderking Caging Products (Millersville, MD, USA) and adapted for the swivel system used to measure MAP and HR. Food and water were available ad libitum at all stages of experimentation. Food was given in pellet form to mice during experimentation. Average weight loss during habituation was $5 \pm 3 \%$ of body weight. Following habituation, mice were taken out of metabolism cages and housed individually in standard cages for 1-2 weeks until surgery for carotid artery catheter implantation commenced. Following catheter implantation, mice recovered individually in standard clear Perspex cages, approximately $26 \times 20 \mathrm{~cm}^{2}$ in size. Metabolism cages and standard cages shared a similar location in the same room during the entire experiment. All experiments were conducted in a 12-h light-dark cycle at $22 \pm 1{ }^{\circ} \mathrm{C}$ and humidity of $50 \pm 5 \%$.

\section{Arterial pressure measurement}

At approximately 37 weeks of age, mice underwent surgery for implantation of a catheter in the left carotid artery for long-term measurement of MAP and HR. This procedure has been described in detail previously (Fitzgerald et al. 2007). Following recovery, catheters and mice were attached to a counter-weighted infusion swivel, allowing continuous infusion of heparinized saline, whilst allowing free movement around the cage. Mice were allowed to recover for 5 days in standard clear Perspex sawdust-bedded cages where they were housed individually, but were able to see other mice on both sides of their cage. Mice were then placed in metabolism cages for 2 days. In these cages, animals are in close proximity to other animals, but cannot actually see each other. MAP and HR were measured in standard cages on Day 5, and in metabolism cages on Day 6 and 7 post-surgery. Data were obtained as 2-second averages of MAP and HR. All mice were placed in metabolism cages at 17:00 $\pm 3 \mathrm{~h}$. Mice were processed in batches, so that 5 mice were placed individually in the metabolism cages at one time. For analysis of the immediate effects of metabolism cage switch on hourly MAP and HR, the baseline period was defined as the $7 \mathrm{~h}$ prior to mice being placed in metabolism cages. For analysis of changes in daily MAP and HR, the baseline period was taken as the $24 \mathrm{~h}$ period prior to cage switch.

\section{Statistical analyses}

Hourly and 24-h MAP and HR data were 


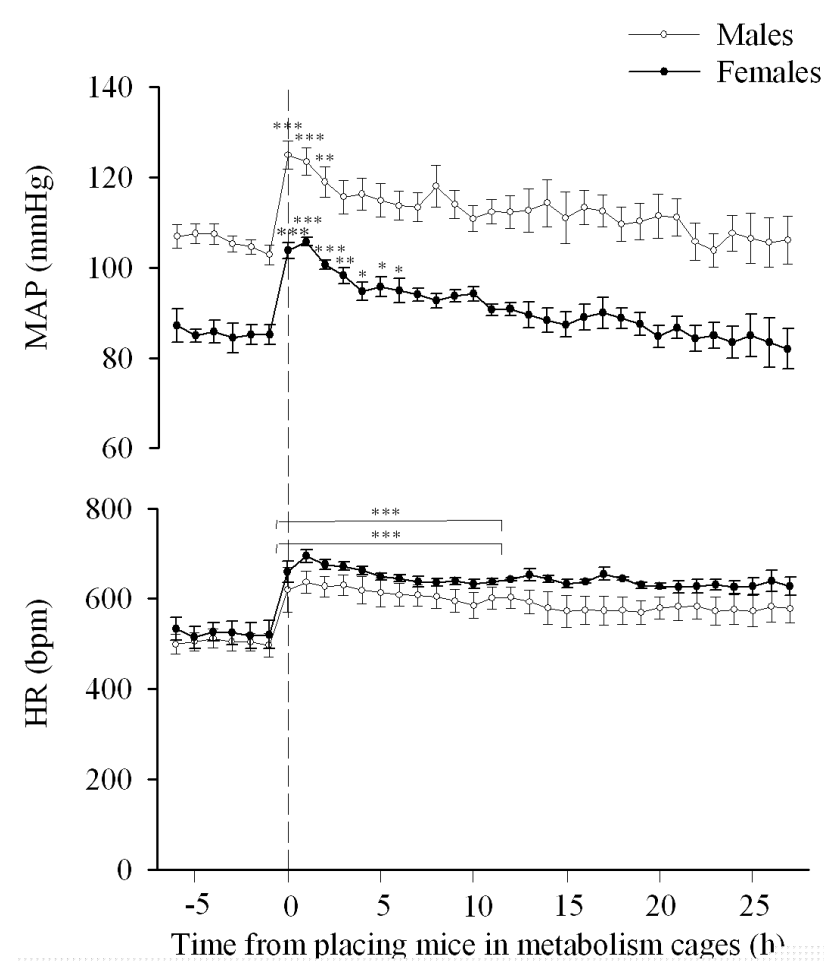

Fig. 1. Effects of placing mice in metabolism cages on hourly MAP and HR. After 5 days of recovery following implantation of a carotid artery catheter, mice were placed in metabolic cages (Time 0 on X-axis). Mean arterial pressure (MAP) and heart rate (HR) are average hourly values before and after placing mice in metabolism cages. Comparisons between baseline and the subsequent $11 \mathrm{~h}$ after mice were placed in metabolism cages were made with Dunnett's post hoc test with each sex analyzed separately. Baseline was taken as an average of the $7 \mathrm{~h}$ before mice were placed in metabolism cages. Values are mean \pm S.E.M. $* * * \mathrm{P}<0.001, * * \mathrm{P}<0.01, * \mathrm{P}<0.05$ for the outcomes of Dunnett's post-hoc test using values over the first $11 \mathrm{~h}$ after the mice were placed in metabolism cages (13 male and 7 female mice aged about 37 weeks).

subjected to repeated measures analysis of variance (Ludbrook 1994). Factors in the analyses comprised sex and time. Our biological hypotheses were that MAP and HR (i) differed according to sex (main effect of sex), (ii) changed in response to housing in metabolism cages (main effect of time) and, (iii) that the response to housing in metabolism cages differed in the two sexes (sex*time interaction). Data for hourly MAP and HR were then subjected to Dunnett's post hoc test with the sexes analyzed separately. $\mathrm{P}<0.05$ was taken to demonstrate statistical significance. Values are mean \pm S.E.M.

\section{Results}

During the $7 \mathrm{~h}$ before mice were placed in metabolism cages MAP was $106 \pm 2$ and $86 \pm 2 \mathrm{~mm} \mathrm{Hg}$, respectively, in males and females. MAP increased

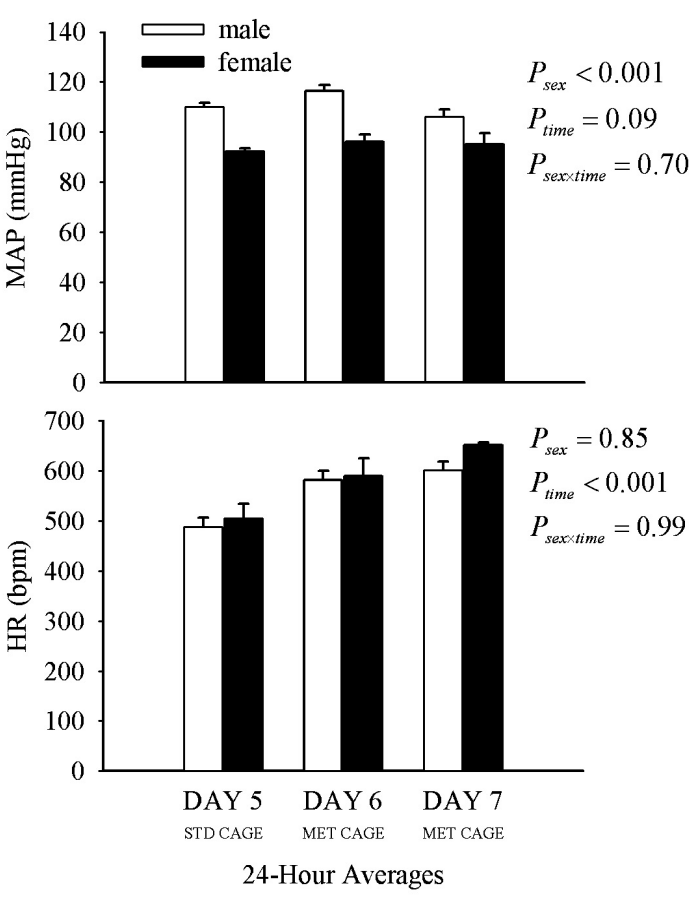

Fig. 2. Effects on 24-h MAP and $H R$ of placing mice in metabolism cages. Basal mean arterial pressure (MAP) and basal heart rate (HR) are 24-h averages of measurements on the fifth day after carotid artery implantation while mice were housed individually in standard cages (STD CAGE). On Day 6 and 7 following surgery, male (open bars) and female (black bars) mice were housed in metabolic cages (MET CAGE). Data were analyzed by 2-way repeated measures analysis of variance (ANOVA) testing for the effects of sex, time and the interaction between these factors on 24-h MAP and HR. Values are mean \pm S.E.M. (13 male and 7 female mice aged about 37 weeks).

significantly in the first hours after metabolism cage switch, by $19 \pm 3 \mathrm{~mm} \mathrm{Hg}(18 \pm 3 \%)$ and $18 \pm 3 \mathrm{~mm} \mathrm{Hg}$ $(22 \pm 4 \%)$ in male and female mice, respectively. In males, MAP was significantly elevated during the first $3 \mathrm{~h}$ after metabolism cage switch (Fig. 1). In females, MAP was significantly elevated during the first $7 \mathrm{~h}$ after metabolism cage switch. Basal HR was $505 \pm 20$ and $524 \pm 23 \mathrm{bpm}$ in males and females, respectively. HR increased by $135 \pm 17$ $\operatorname{bpm}(27 \pm 4 \%)$ and $136 \pm 27 \mathrm{bpm}(27 \pm 6 \%)$ in the first hours after metabolism cage switch in males and females, respectively. In the $11^{\text {th }} \mathrm{h}$ after metabolism cage switch, HR was still significantly greater than baseline in both sexes (Fig. 1). Two-way repeated measures analysis of variance demonstrated a significant effect of sex on MAP $\left(\mathrm{P}_{\mathrm{sex}}<0.001\right)$, reflecting the fact that females had lower MAP than males. However, HR was not different between the sexes $\left(\mathrm{P}_{\mathrm{sex}}=0.36\right)$. The effects of metabolism cage switch on hourly MAP and HR were not sex-dependent $\left(\mathrm{P}_{\text {sex*time }} \geq 0.91\right)$.

MAP averaged $110 \pm 2$ and $93 \pm 1 \mathrm{~mm} \mathrm{Hg}$ over the $24 \mathrm{~h}$ (Day 5) before metabolism cage switch in males and 
females, respectively (Fig. 2). Females had significantly lower MAP than males across all days of MAP measurement $\left(\mathrm{P}_{\mathrm{sex}}<0.001, \mathrm{P}_{\text {sex }^{*} \text { time }}=0.70\right)$. There was no significant effect of metabolism cage switch on daily MAP $\left(\mathrm{P}_{\text {time }}=0.09\right)$. HR averaged $488 \pm 19$ and $505 \pm 29 \mathrm{bpm}$ over the $24 \mathrm{~h}$ (Day 5) before metabolism cage switch in males and females, respectively (Fig. 2). There was no significant effect of sex on 24-h HR $\left(\mathrm{P}_{\mathrm{sex}}=0.85\right)$. HR increased in a sustained fashion during the two-day period of housing in metabolism cages $\left(\mathrm{P}_{\text {time }}<0.001\right.$ ), but this effect was indistinguishable in the two sexes $\left(\mathrm{P}_{\text {sex }}{ }^{*}\right.$ time 0.99, Fig. 2).

\section{Discussion}

Our current study produced two important new findings. Firstly, we found that placing mice in metabolism cages caused a transient increase in MAP in both males and females. MAP returned to baseline within 4-8 h. Secondly, we found that HR increased significantly in both male and female mice after they were placed in metabolism cages. In contrast to the transient nature of the pressor response, this tachycardia was sustained across the $48 \mathrm{~h}$ period of housing in metabolism cages when analyzed as 24-h averages. Our results also demonstrate important sex differences in the hybrid strain of mice we studied, in that MAP was greater in males than females. However, the responses of MAP and HR to metabolism cage switch were not sex-dependent. We conclude that placing mice in this stressful environment, even following habituation, alters cardiovascular and possibly neurohumoral functions in both male and female mice that may in turn alter kidney function.

There is much evidence that stressful environments can alter neurohumoral and cardiovascular function in rats and mice (Gil et al. 1999, Sharp et al. 2002a,b, 2003, Spani et al. 2003, Lee et al. 2004a,b). Furthermore, although there is a dearth of information on the effects of metabolism cage switch on cardiovascular function in rats and mice, changes in neurohumoral and metabolic function have been reported in rats (GomezSanchez and Gomez-Sanchez 1991, Brunner et al. 1994, Gil et al. 1999, Armando et al. 2001, Eriksson et al. 2004, Armando et al. 2007). For example, Armando et al. (2007) recently reported greater anterior pituitary adrenocorticotrophin hormone content and adrenal corticosterone content in rats placed individually in metabolism cages compared to rats housed in standard cages. They also found enhanced angiotensin II Type 1 receptor expression in the paraventricular nucleus in response to placing animals in metabolic cages combined with individual confinement (Armando et al. 2001, 2007). Nevertheless, we are aware of no previous study which has determined the cardiovascular effects of placing male and female mice in metabolism cages. The transient pressor response to metabolism cage switch is unlikely to be a major confounding factor in studies of renal function. However, the sustained tachycardic response suggests that there are persistent changes in neural and/or hormonal function in these mice during housing in metabolism cages which could confound the interpretation of renal function measurements. Consistent with this proposition, housing of rats in metabolism cages has been shown to result in decreased urine flow and altered creatinine clearance (Vadiei et al. 1990).

There is strong evidence that group housing, as opposed to individual housing of rats or mice, minimizes responses to stress (Sharp et al. 2002a, 2003, Spani et al. 2003). Thus it is likely that both isolation per se and the novelty of the metabolism cage environment contribute to the stress-like responses in metabolism cage studies of isolation stress. As our mice were housed individually for an extended period ( $\sim 2$ weeks) prior to being placed in metabolism cages, the resultant increase in MAP and HR can be attributed to the effects of the environment of the metabolism cage itself, rather than the effects of isolation.

Our current findings show important sex differences in basal cardiovascular function in the C57BL/6/129sv hybrid strain we studied. Previous reports of cardiovascular function in mice derived from the C57BL/6 strain crossed with the 129 strain have not reported arterial pressure separately for the sexes (Krege et al. 1995). We found that females had lower resting MAP than males but similar HR. Previous studies investigating sex differences in basal MAP have shown somewhat conflicting results that appear highly dependent on the strain of mice used (Deschepper et al. 2004, Yang et al. 2005). For example, one study showed similar systolic blood pressure (SBP) in males and females of 9 out of 13 mouse strains studied (Deschepper et al. 2004). However, female C57BL/6J mice had higher SBP than males (Deschepper et al. 2004). The responses of MAP and HR to metabolism cage switch were indistinguishable in our notably older male and female mice in our current study. This has important implications for the interpretation of metabolism cage studies in mice, since it indicates that potentially confounding effects of metabolism cage switch-induced 
changes in neurohumoral function occur in both sexes.

Habituation of mice to their novel environment prior to the experiment is an important consideration in metabolism cage studies. Previous studies using metabolism cages have acclimatized mice and rats for anywhere from 2 days to 3 weeks (Gomez-Sanchez and Gomez-Sanchez 1991, Lee et al. 1998, Chen et al. 2005). Habituation or acclimatization has also been attempted in isolation studies in mice and rats (Gil et al. 1999, Spani et al. 2003) and social stress studies (Bhatnagar et al. 2006), although adaptation to potentially stressful environments does not always occur. For example, Heidbreder et al. (2000) found that rats reared in groups in wire grid floor cages had greater plasma corticosterone levels than rats reared in groups in sawdust cages, despite 12 weeks acclimatization to housing conditions. Thus, while habituation may be an important consideration in studies using metabolism cages, habituation protocols may not always prevent confounding effects of stressful situations. In the present study, mice were habituated at least one week prior to MAP and HR measurement, as the necessary 5-day recovery period following surgery prevented habituation immediately prior to experimental measurements. Our results indicate that the $24 \mathrm{~h}$ habituation protocol we used was not effective in preventing the subsequent stress responses to metabolism cage switch. However, the above discussed results of Heidbreder et al. (2000) suggest that the aim of complete habituation may be problematic.

An important consideration for metabolism cage studies is the potential effect of temperature on neurohumoral control of cardiovascular and renal function. Even small decreases in ambient temperature can increase MAP and HR (Swoap et al. 2004). At ambient temperatures below $29-33{ }^{\circ} \mathrm{C}$ the regulation of body temperature in mice likely depends on activation of neuroendocrine mechanisms that stimulate thermogenesis, in part through activation of the sympathetic nervous system (Overton and Williams 2004). In the current study, following recovery in sawdust-bedded cages, mice were placed in steel metabolism cages in the same room, which had a temperature of $22 \pm 1{ }^{\circ} \mathrm{C}$ and humidity of $50 \pm 5 \%$. Because steel is a good conductor of heat, the metabolism cage environment likely reduced the ability of the mice to maintain body temperature. Thus, future studies should investigate the effects of altered ambient temperature on renal and cardiovascular function during housing of mice in metabolism cages.

In conclusion, the present findings indicate that placing adult mice in metabolism cages, at least under the current experimental conditions, causes a transient increase in MAP and a sustained increase in HR. Whilst MAP returns to normal within hours, the persistent elevation in HR suggests the presence of altered neural and/or hormonal function. These dramatic changes to cardiovascular function may confound the findings of metabolism cage studies of renal physiology. Hence, strategies to reduce the stress of this novel environment should be implemented in such studies.

\section{Conflict of Interest}

There is no conflict of interest.

\section{Acknowledgements}

The authors acknowledge the technical assistance of Ms Jessica Cox. This research was supported by a project grant from the National Health and Medical Research Council of Australia (NHMRC; 384207) and by an Australian Postgraduate Award $(\mathrm{CCH})$ through the Commonwealth Government of Australia. RGE is supported by a NHMRC Senior Research Fellowship (384101), while NHMRC Career Development Awards provide salaries for KMM (384279) and SMF (334068).

\section{References}

ARMANDO I, CARRANZA A, NISHIMURA Y, HOE KL, BARONTINI M, TERRON JA, FALCON-NERI A, ITO T, JUORIO AV, SAAVEDRA JM: Peripheral administration of an angiotensin II $\mathrm{AT}_{1}$ receptor antagonist decreases the hypothalamic-pituitary-adrenal response to isolation stress. Endocrinology 142: 3880-3889, 2001.

ARMANDO I, VOLPI S, AGUILERA G, SAAVEDRA JM: Angiotensin II AT 1 receptor blockade prevents the hypothalamic corticotropin-releasing factor response to isolation stress. Brain Res 1142: 92-99, 2007.

BAE SK, KIM EJ, KWON JW, KIM WB, LEE I, LEE MG: Excretion, metabolism of DA-7867, a new oxazolidinone, in rats. Biopharm Drug Dispos 26: 67-75, 2005. 
BAMBERG E, PALME R, MEINGASSNER JG: Excretion of corticosteroid metabolites in urine, faeces of rats. Lab Anim 35: 307-314, 2001.

BHATNAGAR S, VINING C, IYER V, KINNI V: Changes in hypothalamic-pituitary-adrenal function, body temperature, body weight, food intake with repeated social stress exposure in rats. J Neuroendocrinol 18: 1324, 2006.

BOSQUE MA, DOMINGO JL, CORBELLA J: Housing of pregnant rats in metabolism cages: maternal, developmental effects. Exp Toxicol Pathol 46: 303-306, 1994.

BRUNNER LJ, DIPIRO JT, FELDMAN S: Metabolic cage isolation reduces antipyrine clearance in rats. $J$ Pharm Pharmacol 46: 581-584, 1994.

CHEN Q, TAKAHASHI S, ZHONG S, HOSODA C, ZHENG HY, OGUSHI T, FUJIMURA T, OHTA N, TANOUE A, TSUJIMOTO G, KITAMURA T: Function of the lower urinary tract in mice lacking alpha $\mathrm{1D}_{\mathrm{D}}$-adrenoceptor. J Urol 174: 370-374, 2005.

DAULL P, BENREZZAK O, ARSENAULT D, PHENG LH, BLOUIN A, CAYER J, BEAUDOIN M, BELLEVILLE $\mathrm{K}$, SIROIS P, NANTEL F, JENG AY, BATTISTINI B: Triple vasopeptidase inhibition normalizes blood pressure in conscious, unrestrained, spontaneously hypertensive rats. Am J Hypertens 18: 1606-1613, 2005a.

DAULL P, BLOUIN A, CAYER J, BEAUDOIN M, BELLEVILLE K, SIROIS P, NANTEL F, CHANG TM, BATTISTINI B: Profiling biochemical, hemodynamic markers using chronically instrumented, conscious, unrestrained rats undergoing severe, acute controlled hemorrhagic hypovolemic shock as an integrated in-vivo model system to assess new blood substitutes. Vascul Pharmacol 43: 289-301, 2005b.

DESCHEPPER CF, OLSON JL, OTIS M, GALLO-PAYET N: Characterization of blood pressure, morphological traits in cardiovascular-related organs in 13 different inbred mouse strains. J Appl Physiol 97: 369-376, 2004.

ERIKSSON E, ROYO F, LYBERG K, CARLSSON HE, HAU J: Effect of metabolic cage housing on immunoglobulin A, corticosterone excretion in faeces, urine of young male rats. Exp Physiol 89: 427-433, 2004.

FENTON RA, FLYNN A, SHODEINDE A, SMITH CP, SCHNERMANN J, KNEPPER MA: Renal phenotype of UTA urea transporter knockout mice. J Am Soc Nephrol 16: 1583-1592, 2005.

FENTON RA, KNEPPER MA: Urea, renal function in the 21st century: insights from knockout mice. $J$ Am Soc Nephrol 18: 679-688, 2007.

FITZGERALD SM, KEMP-HARPER BK, PARKINGTON HC, HEAD GA, EVANS RG: Endothelial dysfunction, arterial pressure regulation during early diabetes in mice: roles for nitric oxide, endothelium-derived hyperpolarizing factor. Am J Physiol 293: R707-R713, 2007.

GIL MC, AGUIRRE JA, LEMOINE AP, SEGURA ET, BARONTINI M, ARMANDO I: Influence of age on stress responses to metabolic cage housing in rats. Cell Mol Neurobiol 19: 625-633, 1999.

GOMEZ-SANCHEZ EP, GOMEZ-SANCHEZ CE: 19-Nordeoxycorticosterone, aldosterone,, corticosterone excretion in sequential urine samples from male, female rats. Steroids 56: 451-454, 1991.

HEIDBREDER CA, WEISS IC, DOMENEY AM, PRYCE C, HOMBERG J, HEDOU G, FELDON J, MORAN MC, NELSON P: Behavioral, neurochemical, endocrinological characterization of the early social isolation syndrome. Neuroscience 100: 749-768, 2000.

KREGE JH, HODGIN JB, HAGAMAN JR, SMITHIES O: A noninvasive computerized tail-cuff system for measuring blood pressure in mice. Hypertension 25: 1111-1115, 1995.

LEE DL, LEITE R, FLEMING C, POLLOCK JS, WEBB RC, BRANDS MW: Hypertensive response to acute stress is attenuated in interleukin-6 knockout mice. Hypertension 44: 259-263, 2004a.

LEE DL, WEBB RC, BRANDS MW: Sympathetic, angiotensin-dependent hypertension during cage-switch stress in mice. Am J Physiol 287: R1394-R1398, 2004b.

LEE KM, REED LL, BOVE DL, DILL JA: Effects of water dilution, housing, food on rat urine collected from the metabolism cage. Lab Anim Sci 48: 520-525, 1998.

LEUNG YY, SCHWARZ EM, SILVERS CR, MESSING EM, WOOD RW: Uroflow in murine urethritis. Urology 64: 378-382, 2004.

LUDBROOK J: Repeated measurements, multiple comparisons in cardiovascular research. Cardiovasc Res 28: 303$311,1994$. 
OVERTON JM, WILLIAMS TD: Behavioral, physiologic responses to caloric restriction in mice. Physiol Behav 81: 749-754, 2004.

SAKLY R, BARDAOUI M, NEFFATI F, MOUSSA A, ZAKHAMA A, NAJJAR MF, HAMMAMI M: Effect of hyperprotidic diet associated or not with hypercalcic diet on calcium oxalate stone formation in rat. Ann Nutr Metab 49: 132-138, 2005.

SHARP J, ZAMMIT T, AZAR T, LAWSON D: Stress-like responses to common procedures in individually, grouphoused female rats. Contemp Top Lab Anim Sci 42: 9-18, 2003.

SHARP JL, ZAMMIT TG, AZAR TA, LAWSON DM: Stress-like responses to common procedures in male rats housed alone or with other rats. Contemp Top Lab Anim Sci 41: 8-14, 2002a.

SHARP JL, ZAMMIT TG, LAWSON DM: Stress-like responses to common procedures in rats: effect of the estrous cycle. Contemp Top Lab Anim Sci 41: 15-22, 2002b.

SPANI D, ARRAS M, KONIG B, RULICKE T: Higher heart rate of laboratory mice housed individually vs in pairs. Lab Anim 37: 54-62, 2003.

SWOAP SJ, OVERTON JM, GARBER G: Effect of ambient temperature on cardiovascular parameters in rats, mice: a comparative approach. Am J Physiol 287: R391-R396, 2004.

VADIEI K, BERENS KL, LUKE DR: Isolation-induced renal functional changes in rats from four breeders. Lab Anim Sci 40: 56-59, 1990.

XUE B, PAMIDIMUKKALA J, HAY M: Sex differences in the development of angiotensin II-induced hypertension in conscious mice. Am J Physiol 288: H2177-H2184, 2005.

YANG T, HUANG YG, YE W, HANSEN P, SCHNERMANN JB, BRIGGS JP: Influence of genetic background, gender on hypertension, renal failure in COX-2-deficient mice. Am J Physiol 288: F1125-F1132, 2005. 